\title{
Response of earthworms to light as measured by the GSR
}

ROBERT F. MORGAN, STANLEY C. RATNER AND M. RAY DENNY

MICHIGAN STATE UNIVERSITY

\begin{abstract}
Abstraet
Four groups of earthworms, Lumbricus terrestris, were prepared for recording with the GSR. Each group received four widely spaced trials of photic stimulation. Stimulation intensities ranged from 480 f.c. (No. 2 photo-flood) to 0 f.c. Results indicated gradual habituation of the GSR for all Ss. GSR changes to photic stimulation involved increases in resistance whose magnitudes were a joint function of intensity of stimulation and the number of trials. Magnitude of GSR responses varied positively with intensity and negatively with number of trials. Control Ss were tested to calibrate and verify the GSR recordings.
\end{abstract}

\section{Introduction}

The unconditioned response of earthworms to light is a complex function of a number of variables including light intensity and number of prior presentations (Hess, 1924; Ratner \& Stein, 1965). Very low intensity elicits movement toward light, positive responses; moderate and high intensities elicit movement away from light, negative responses. Repeated presentations elicit progressively fewer responses. However, detailed analysis of changes in responses as a function of these variables is not possible from observation of the worm's movements alone. Preliminary study indicated that apparatus to measure galvanic skin response (GSR) was appropriate for detailed study of changes in worms' responses to light. The present study was designed to investigate effects of stimulus intensity and repeated trials on the GSR of earthworms.

Method

Thirty-six earthworms, Lu mbricus terrestris, were selected from a large colony box of Ss obtained from a local bait supply store and maintained in a refrigerator at Michigan State University. Eight Ss were assigned randomly to each experimental group and four were used as control Ss to test the apparatus.

The apparatus consisted of surgical materials to sew each $\mathrm{S}$ to a sponge; a Lafayette AC-DC GSR amplifier, Model $601 \mathrm{~A}$ with finger electrodes; one refrigerator to store $\mathrm{Ss}$ at $50^{\circ} \mathrm{F}$; one refrigerator to test Ss at $50^{\circ} \mathrm{F}$; one reflector lamp with light bulbs of 480 f.c., 180 f.c., and 150 f.c.; a heat filter consisting of a bowl of cold water placed between the light and the test animal; stop watches for timing stimulus durations and interstimulus intervals.

Each experimental $\mathrm{S}$ was removed from the colony box and placed in an anaesthetic solution of $2 \mathrm{ml}$ of $5 \%$ chlorotone solution for about $15 \mathrm{~min}$. The $\mathrm{S}$ was then laid on a 4 in $\times 6$ in foam rubber sponge and sewed onto the sponge with a curved needle and No. 50 thread. The stitches were run through the epidermis and into the sponge. The first stitch was just anterior to the clitellum; others were spaced 1 in apart to within several segments before the anus. The worm on the sponge was returned to the refrigerator for $48 \mathrm{hr}$. A wet sponge was laid over $S$ and sphagnum moss (food) was placed by the mouth. The four apparatus test Ss were fatally anaesthetized, sewed onto sponges, and then used to test for recorder changes.

After the $48 \mathrm{hr}$. recovery period, the $\mathrm{S}$ on its sponge was placed in a refrigerator for testing. The laboratory and test areas were illuminated by an 8-w ruby-red bulb. One GSR electrode was placed in front of the clitellum: the other behind it ( 1 in apart). A heat filter of cold water was placed above $S$ and a lamp with the appropriate bulb was placed 22 in above $\mathrm{S}$. The door of the refrigerator containing $S$ was closed and GSR recording was begun. After $15 \mathrm{~min}$. the first photic stimulus was turned on for $60 \mathrm{sec}$.; this was repeated three more times with a $5 \mathrm{~min}$. ITI. The $\mathrm{S}$ was removed after $34 \mathrm{~min}$. at the conclusion of the last stimulus. The following groups were run: group 1-No. 2 photoflood bulb (480 f.c); group 2-300-w bulb (180 f.c.); group 3-150-w bulb (80 f.c.); group 4-0-w bulb (0 f.c.). One dead control $\mathrm{S}$ was run through the procedure at each intensity level.

The DC circuit of the GSR apparatus was used so that resistance changes in ohms to the nearest thousand were read directly from the resistance dial every $60 \mathrm{sec}$. during the S's run. The latency of the GSR of worms to light onset is 15 to $20 \mathrm{sec}$., so that the reading at the onset of light does not include the response to the light. All resistance changes were transformed to square root of conductance called GSR units (Schlosberg \& Stanley, 1953). For statistical analyses 0.1 GSR units were subtracted from each transformed score for Ss in group 1 because the apparatus control worm showed a 0.1 GSR unit change under the highest level of illumination. Temperature change may have led to this.

\section{Results}

The main results are shown in Fig. 1. Since the groups differed in GSR response prior to stimulation, analyses of covariance were used in statistical tests. In general a gradual drop in GSR occurred that reached asymptote after about $22 \mathrm{~min}$. (group 4). Presentation of light led to an increase in GSR on the first trial for groups 1, 2, and 3. The amount of increase varied significantly with the intensity of the stimulus. However, 


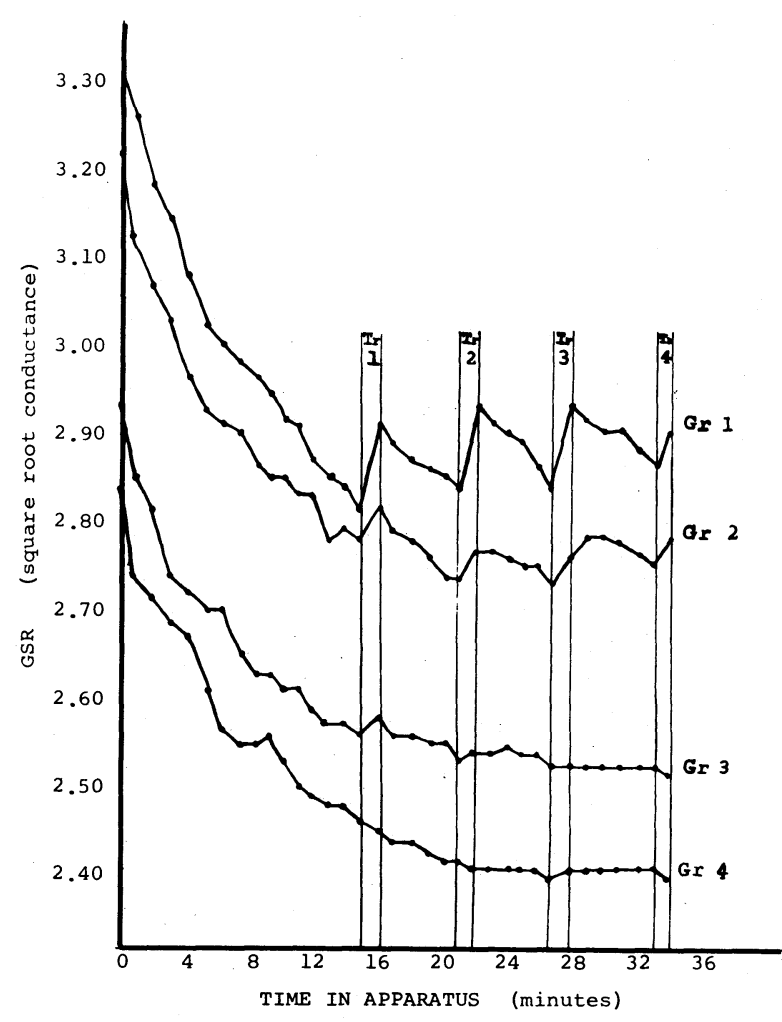

Fig. 1. Mean GSR readings for each group as a function of time in the apparatus. Trials $1,2,3,4$ are trials with stimulation appropriate for the group. subsequent presentations of the stimulus led to progressively smaller changes in GSR so that by trial 3, group 3 showed no response. Analysis of covariance verified the significant interaction between trials and intensity. This agrees with Davis' finding (1930) using humans.

These results suggest the validity of the GSR as a measure of response to photic stimulation. Coonfield (1932) found that epidermal changes involving mucous secretions and contractions of the body wall occurred together whenever worms are stimulated. One or both of these components of this defensive response may be the change that is being measured by the GSR with earthworms.

\section{References}

Coonfield, B. R. The peripheral nervous system of earthworms. J. comp. Neurol., 1932, 55, 7-17.

Davis, R. C. Factors affecting the galvanic reflex. Arch. Psychol., N. Y., 1930, No. 115

Hess, W. N. Reactions to light in the earthworm, L. terrestris. J. morph. Physiol., 1924, 39, 515-542.

Morgan, R. F. The GSR of earthworms as a function of photic intensity and number of trials. Unpublished MA thesis, Michigan State University, 1964.

Ratner, S. C., \& Stein, D. G. Responses of worms to light as a function of intertrial interval and ganglion removal. J. comp. physiol. Psychol., 1965, 59, 301-305.

Schlosberg, H., \& Stanley, W. C. A simple test of the normality of twenty-four distributions of electrical skin conductance. Science, $1953,117,35-37$.

\section{Note}

1. This research is a portion of thesis submitted by R. F. Morgan to Michigan State University in partial fulfillment of the requirements for a MA degree. The research was supported by Public Health Fellowship, 5 F1 MH-21, 649-02 to R. F. Morgan. Preparation of the manuscript and some laboratory facilities were supported by NSF grant GB-917 to S. C. Ratner. The research was directed by M. Ray Denny. 